\title{
Enolase-phosphatase 1 as a novel potential malignant glioma indicator promotes cell proliferation and migration
}

\author{
LI SU ${ }^{1,2}$, KE YANG $^{3}$, SHUN LI $^{1}$, CHEN LIU $^{1}$, JIANGUO HAN ${ }^{2}$, YUAN ZHANG $^{3,4}$ and GUOZHENG XU ${ }^{1}$ \\ 1Department of Neurosurgery, Wuhan General Hospital of PLA, Southern Medical University, Wuhan, Hubei 430070; \\ ${ }^{2}$ Department of Neurosurgery, Shenzhen University General Hospital, Shenzhen, Guangdong 518055; \\ ${ }^{3}$ The Central Laboratory, The First Affiliated Hospital of Shenzhen University, Shenzhen Second People's Hospital, \\ Shenzhen, Guangdong 518035; ${ }^{4}$ Department of Pathophysiology, Baotou Medical College, Baotou 014010, P.R. China
}

Received February 5, 2018; Accepted July 17, 2018

DOI: $10.3892 /$ or.2018.6592

\begin{abstract}
Enolase-phosphatase 1 (ENOPH1), is an enzyme that is involved in polyamine biosynthesis and is associated with stress responses. However, little is known about its role in the pathophysiology of glioma. In the present study, we examined the expression and function of ENOPH1 in human glioma tissues and cell lines. Western blot, qPCR and immunohistochemistry analysis were performed to investigate the expression of the ENOPH1 protein in glioma tissues in 86 patients. The 3-[4,5-dimethylthiazol-2-yl]-2,5-diphenyl tetrazolium bromide (MTT), wound healing and cell cycle assays were implemented to identify cell growth and cell migration in U87 and U251 glioma cells. The results revealed that compared with normal brain tissues, the level of ENOPH1 was markedly increased in glioma tissues. In addition, we observed that the glioma pathological grade was positively associated with the expression level of ENOPH1. Knockdown of ENOPH1 expression with siRNA markedly reduced cell proliferation, and significantly decreased cell migration. Notably, knockdown of ENOPH1 promoted its downstream protein, aci-reductone dioxygenase 1 (ADI1), to shift from the nucleus to the cytoplasm of U251 glioma cells, while MT1-MMP expression was
\end{abstract}

Correspondence to: Dr Guozheng Xu, Department of Neurosurgery, Wuhan General Hospital of PLA, 627 Wuluo Road, Wuhan, Hubei 430070, P.R. China

E-mail: yaoshun2008@yeah.net

Dr Yuan Zhang, The Central Laboratory, The First Affiliated Hospital of Shenzhen University, Shenzhen Second People's Hospital, 3002 Sungang West Road, Shenzhen, Guangdong 518035, P.R. China E-mail: susanyuan821@163.com

Abbreviations: MGMT, $O$-6-methylguanine-DNA methyltransferase; EGFR, epidermal growth factor receptor; EDTA, eathylene diamine tetraacetic acid; PBS, phosphate buffered saline; BSA, bovine albumin; DAPI, 4',6-diamidino-2-phenylindole; FITC, fluorescein isothiocyanate; SDS, sodium dodecyl sulfate; RIPA, radio-immunoprecipitation assay

Key words: enolase-phosphatase 1, proliferation, glioma, aci-reductone dioxygenase 1 , migration, membrane type 1-matrix metalloproteinase significantly downregulated compared with the control group. Collectively, our data demonstrated that the knockdown of ENOPH1 suppressed cell growth and migration, which may be associated with ADI1 translocation and MT1-MMP downregulation in glioma cells. Thus, ENOPH1 could serve as an underlying therapeutic target of glioma.

\section{Introduction}

Glioma is the most common and the most lethal brain tumor in the adult central nervous system, with characteristics of being highly heterogeneous, having a strong invasive ability and radiotherapy and chemotherapy resistance (1). Due to the fact that its pathogenesis is not completely clear, there is still a lack of effective treatments for glioma. Using radiotherapy combined with temozolomide, we treated newly diagnosed glioblastoma, which doubled the 2-year survival rate of patients up to $27 \%$ (2). However, the patient overall prognosis remains poor. In addition to the traditional diagnostic criteria for histopathology, molecular diagnostics play a vital part in the auxiliary typing of glioma, incorporating the information about the entire deletions of $1 \mathrm{p} / 19 \mathrm{q}$, the shifts in the EGFR signaling pathway, and the gene mutations of MGMT promoter methylation and isocitrate dehydrogenases 1 (IDH1) $(3,4)$. A large and growing body of literature has investigated new molecular biomarkers in glioma that satisfied the needs of precise treatment for glioma $(5,6)$. Emerging evidence demonstrates that the activation of amino acid biosynthetic pathways has an important role in the progression of cancer $(7,8)$.

Enolase-phosphatase 1 (ENOPH1, also called $\mathrm{mtnC}$ ) is a new enzyme of research interest, which is not only involved in the synthesis of polyamine, but is also required for methionine remediation synthesis (9). Recently, Barth et al (10) found that ENOPH1 was extensively expressed in the brain and that ENOPH1 protein levels in the brain tissue of C57BL/6J mice could be enhanced by stress responses (10). Polyamines are present in all eukaryotic cells, their synthesis is closely related to cell growth or tumor cell proliferation and play a key role in regulating tumor cell differentiation $(11,12)$. Polyamine accumulation has a significant effect on glioma growth (13). Since ENOPH1 participates indirectly via S-adenosyl methionine (SAM) in the synthesis of polyamine (14-17), we 
can logically conclude that ENOPH1 has a role in glioma. However currently, the mechanisms controlling the expression and function of ENOPH1 in glioma are not well understood.

Thus, in the present study, we used in vitro cultured human glioma cell lines and in vivo human glioma tissues to explore the role of ENOPH1 in glioma progression. Apart from evaluating the expression pattern of ENOPH1 gene and protein, we also examined the effect of targeted silencing of the ENOPH1 gene in glioma cell proliferation and migration. Our data revealed that ENOPH1 was upregulated in human glioma cell lines, and glioma samples and knockdown of ENOPH1 decreased glioma cell proliferation and migration along with translocation of its downstream protein aci-reductone dioxygenase 1 (ADI1) and downregulation of membrane type 1-matrix metalloproteinase (MT1-MMP).

\section{Materials and methods}

Clinical tissue sample collection. Tumor samples as well as patient clinical-pathological data were acquired from Wuhan General Hospital of PLA (Wuhan, China) between January 2013 and December 2014. All the experiments using the human samples were authorized by the Ethics Committee of Southern Medical University. All patients willingly consented to participate in the study by signing an informed consent form. In terms of the World Health Organization (WHO) classification (18), a total of 86 gliomas were classified as 12 pilocytic astrocytomas (WHO I), 15 diffuse astrocytomas (WHO II), 18 anaplasia astrocytomas (WHO III) and 41 primary glioblastomas (WHO IV). None of the patients had been treated with chemotherapy or radiotherapy before surgery. Resected tumor tissues were snap-frozen in liquid nitrogen and maintained at $-80^{\circ} \mathrm{C}$ and liquid nitrogen before use, and the other tissues were formalin-fixed and paraffin-embedded for conventional histopathology and immunohistochemistry (IHC). Clinical parameters, including age, sex and pathological grading of all patients are presented in Table I. The period of follow-up was from 0.2 to 68.4 months.

IHC. Immunohistochemical staining was performed as previously mentioned (19). The tissues sections were formalin-fixed and paraffin-embedded. The sections were deparaffinized in xylene and rehydrated by graded alcohol to water, and by incubating the slides in $3 \% \mathrm{H}_{2} \mathrm{O}_{2}$ in water at room temperature for $30 \mathrm{~min}$ endogenous peroxidase activity was eliminated. Subsequently, after being incubated in $1 \%$ BSA for $30 \mathrm{~min}$, the sections were wiped off, and then a dilution of anti-ENOPH1 (1:250; cat. no. sc-365155; Santa Cruz Biotechnology, Inc., Dallas, TX, USA) was applied to the slides and incubated at room temperature overnight. Subsequently, the slides were incubated at room temperature with a secondary antibody (1:1,000; cat. no. 323-005-021; Jackson ImmunoResearch Labs, West Grove, PA, USA) for $2 \mathrm{~h}$, following the manufacturer's instructions. At the same concentration as for the primary antibody (ENOPH1; 1:250; cat. no. sc-365155; Santa Cruz Biotechnology), the negative control slides were processed in parallel with a non-specific immunoglobulin IgG (Sigma-Aldrich; Merck KGaA, Darmstadt, Germany). Finally, the stained sections were examined under a light microscope (Leica Microsystems, Wetzlar, Germany).
Cell culture and transfection. The human glioma cell lines U87 and U251 were obtained from the Type Culture Collection of the Chinese Academy of Sciences (Shanghai, China). The U87 cell line is glioblastoma of unknown origin. The glioma cells were grown in Dulbecco's modified Eagle's medium (DMEM) supplemented with $10 \%$ fetal bovine serum (FBS) (both from Gibco; Thermo Fisher Scientific, Inc., Waltham, MA, USA) at $37^{\circ} \mathrm{C}$ in humidified $5 \% \mathrm{CO}_{2} / 95 \%$ air. To obtain cells in the exponential growth phase, cell cultures for the assays were initiated at a density of $5 \times 10^{5}$ cells $/ \mathrm{ml}$. We used a haemocytometer (Adam MC; Digital Bio, Seoul, Korea) to count the number of cells. Following the manufacturer's instructions, at 60-70\% confluence on dishes of different sizes (Corning Glass Works, Corning, NY, USA), glioma cells were transfected with 100 nM ENOPH1 siRNA (si-ENOPH1; cat. no. sc-88932) or scrambled control siRNA (si-control; cat. no. sc-37007) with the use of siRNA transfection reagent (cat. no. sc-29528; all from Santa Cruz Biotechnology, Inc.). The cells were not used in the following experiments until $48 \mathrm{~h}$ post-transfection, and the specific silencing effect was verified by western blot analysis. The cell lines have been authenticated by STR profiling.

RNA extraction and quantitative real-time PCR. Total RNA was obtained from glioma cells using TRIzol (Invitrogen; Thermo Fisher Scientific, Inc.) following the manufacturer's instructions. After being reversely transcribed using TaqMan ${ }^{\circledR}$ Reverse Transcription kit and the Vii7 Real-Time PCR System, the products were amplified in a $10-\mu l$ final reaction volume using SYBR $^{\circledR}$ Green PCR Master Mix (all from Applied Biosystems; Thermo Fisher Scientific, Inc.). This was performed under the following conditions: $30 \mathrm{sec}$ at $95^{\circ} \mathrm{C}$, followed by a total of 40 cycles of two temperature cycles $\left(15 \mathrm{sec}\right.$ at $95^{\circ} \mathrm{C}$ and $1 \mathrm{~min}$ at $60^{\circ} \mathrm{C}$ ). The primer sequences used were as follows: human ENOPH1 forward, 5'-AGAAGACTTACTACAGCCTCA-3' and reverse, 5'-AACTACACTTTGCCCTCA-3'; GAPDH served as the endogenous control, and the primers were as follows: forward, 5'-CAATGTGTCCGTCGTGGATCT-3' and reverse, 5'-GTCCTCAGTGTAGCCCAAGATG-3'. Using the SDS Enterprise Database v2.0.6 software (Applied Biosystems; Thermo Fisher Scientific, Inc.), the $\mathrm{Cq}$ value was calculated using the comparative $2^{-\Delta \Delta C \mathrm{Cq}}$ method (20).

Cell viability and proliferation assays. Using a 3-[4,5-dimethylthiazol-2-yl]-2,5-diphenyl tetrazolium bromide (MTT) assay, the viability and proliferation of glioma cells were determined. After being seeded in 96 -well plates $\left(2 \times 10^{3}\right.$ cells/well), the U251 cells were transfected with siRNAs. The cells were cultured for an appropriate time period and then $0.5 \mathrm{mg} / \mathrm{ml}$ MTT (MedChem Express, Monmouth Junction, NJ, USA).

USA) was added to each well and cultured for $4 \mathrm{~h}$ at $37^{\circ} \mathrm{C}$. By measuring the absorption at a wavelength of $490 \mathrm{~nm}$, the number of viable growing cells was calculated after the cells were lysed for $10 \mathrm{~min}$ at $37^{\circ} \mathrm{C}$ in $200 \mu \mathrm{l}$ dimethyl sulfoxide (Sigma-Aldrich; Merck KGaA). This allowed for the establishment of cell growth curves in terms of the optical density (OD) value. The proliferation rate was calculated according to the following formula: survival rate $=(\mathrm{OD}$ test $/ \mathrm{OD}$ negative control) $\mathrm{x} 100 \%$. In addition to being repeated at least three times, all the experiments were performed in triplicate. 
Table I. Clinicopathological characteristics of glioma patients.

\begin{tabular}{lccc}
\hline & & \multicolumn{2}{c}{ ENOPH1 expression } \\
\cline { 3 - 4 } $\begin{array}{l}\text { Clinical } \\
\text { characteristics }\end{array}$ & $\begin{array}{c}\text { Patient } \\
\text { number }\end{array}$ & High, n (\%) & Low, n (\%) \\
\hline Age years & & & \\
$<45$ & 30 & $13(43)$ & $17(57)$ \\
$\geq 45$ & 56 & $25(47)$ & $31(53)$ \\
Sex & & & \\
Male & 45 & $20(45)$ & $25(55)$ \\
Female & 41 & $21(51)$ & $20(49)$ \\
WHO grade & & & \\
I & 12 & $3(25)$ & $9(75)$ \\
II & 15 & $4(27)$ & $11(73)$ \\
III & 18 & $14(78)$ & $4(22)$ \\
IV & 41 & $34(83)$ & $7(17)$ \\
\hline
\end{tabular}

ENOPH1, enolase-phosphatase 1; WHO, World Health Organization.

Cell migration scratch assay. Scratch assays were conducted to determine the glioma cell migration ability. Before being transfected with the control siRNA or the ENOPH1 siRNA (50 nM) $24 \mathrm{~h}$ later, the cells were seeded in 12-well plates ( $2 \times 10^{5}$ cells/well). Next, the cells were cultured for a corresponding time period, treated with colchicine $(10 \mu \mathrm{g} / \mathrm{ml})$ for $1 \mathrm{~h}$, and then a $10-\mu \mathrm{l}$ sterile micropipette tip was used to create an artificial wound. Subsequently, the displaced cells and debris were removed by rinsing the plates with PBS before replacing the culture media. Using ImageJ software (Java 1.8.0_112; NIH, Bethesda, MD, USA) the distance covered by the cells at the leading edge of the wound at each time-point was calculated, and the scratched area was imaged under a fluorescence microscope at 0 and $24 \mathrm{~h}$. The results were reported by percentage of migrated cells.

Cell cycle analysis. DNA content analysis was determined by propidium iodide (PI) staining. In brief, after the cells in each group were washed with PBS twice and centrifuged at $1,000 \mathrm{rpm}$ for $5 \mathrm{~min}$ to adjust their density to $1 \times 10^{6}$ cells/well, cold $70 \%$ ethyl alcohol was added, and the cells were maintained at $4^{\circ} \mathrm{C}$ for overnight fixation. In addition, before being incubated with $400 \mu \mathrm{l}$ PI staining buffer $(50 \mu \mathrm{g} / \mathrm{ml}$; NanJing KeyGen Biotech Co., Ltd., Nanjing, China) at $4^{\circ} \mathrm{C}$ in the dark for $30 \mathrm{~min}$, the fixed cells were washed with PBS, and then, $100 \mu 1$ RNase was added to the sample for incubation for $30 \mathrm{~min}$ at $37^{\circ} \mathrm{C}$. Using a flow cytometer (Beckman Coulter, Brea, CA, USA), the cell cycle distribution was determined, and the percentage of cells in the G1, S and G2/M phases with the FlowJo software (FlowJo V10; Tree Star, Inc., Ashland, OR, USA) was determined. The experiment was performed at least three times.

Western blot analysis. Glioma tissues and glioma cell lines were solubilized in RIPA lysis buffer (Thermo Fisher Scientific, Inc.). With the help of a Pierce ${ }^{\mathrm{TM}}$ BCA Protein
Assay kit (Thermo Fisher Scientific, Inc.) the cell lysates were centrifuged at 12,000 rpm and the protein concentrations were estimated. The cell lysates were separated by electrophoresis on $10-12 \%$ sodium dodecyl sulfate (SDS)-PAGE and $25 \mu \mathrm{g}$ of protein was loaded per lane, before being transferred to polyvinylidene difluoride (PVDF) membranes. The membranes were then blocked in TBS-T containing 5\% non-fat milk for $1 \mathrm{~h}$ at room temprature, and then incubated with primary antibodies overnight. The membranes were washed and incubated with horseradish peroxidase (HRP)-conjugated secondary antibodies (1:1,000; cat. no. 323-005-021; Jackson Immuno Research Labs, West Grove, PA, USA) for $1 \mathrm{~h}$ at room temperature and developed with the use of a chemiluminescence kit (Thermo Fisher Scientific, Inc.). The primary antibodies were ENOPH1 (1:1,000; cat. no. 11763-1-AP), ADI1 (1:2,000; cat. no. ab154689), MT1-MMP (1:1,000; cat. no. ab51074), p21 (1:2,000; cat. no. ab109520), p27 (1:4,000; cat. no. ab32034), cyclin B (1:20,000; cat. no. ab32053), cyclin D (1:30,000; cat. no. ab134175) and $\beta$-actin (1:1,000; cat. no. sc-47778). The anti-ENOPH1 antibody was obtained from ProteinTech Group, Inc. (cat. no. 11763-1-AP; Chicago, IL, USA). In addition, the other primary antibodies were acquired from Abcam (Cambridge, MA, USA). $\beta$-actin was used as an internal standard for overall protein levels.

Immunocytochemistry. The U87 and U251 glioma cells, which were cultured on type I collagen-coated coverslips, were fixed with $4 \%$ paraformaldehyde and permeabilized with $0.1 \%$ Triton X-100 during fixation. After applying a blocking solution (3\% BSA, $0.1 \%$ Tween-20 and 5\% goat serum in PBS) non-specific binding was blocked, and then the cells were cultured with anti-ENOPH1 (1:200) primary antibodies at $4^{\circ} \mathrm{C}$ overnight. Subsequently, FITC anti-mouse secondary antibodies (1:200; Invitrogen; Thermo Fisher Scientific, Inc.) were added and incubated at room temperature for $1 \mathrm{~h}$. After applying the anti-fade sealing solution (Maixin Biotech. Co., Ltd., Fuzhou, China), the coverslips were mounted on glass slides, immunostaining was imaged with the use of a DMI6000B fluorescence microscope (Leica Microsystems $\mathrm{GmbH}$, Wetzlar, Germany). The average fluorescence intensity of ENOPH1 in the cells in the image was determined as previously described (21).

Statistical analysis. With the help of SPSS version 13.0 (SPSS, Chicago, IL, USA), statistical analyses were performed. All the data are presented as the mean values \pm standard deviation (SD). Student's t-test or one-way ANOVA followed by Tukey's post-hoc test was applied to determine significant differences between groups. Overall survival curves were plotted by the Kaplan-Meier method and were compared by log-rank tests. $\mathrm{P}<0.05$ was considered to indicate a statistically significant difference.

\section{Results}

ENOPH1 is upregulated in human glioma tissues. ENOPH1 has been demonstrated to be expressed in a wide range of cells in the brain, including neurons and microvascular endothelial cells, and is involved in stress response and cell apoptosis $(10,21)$. To identify whether ENOPH1 participates 

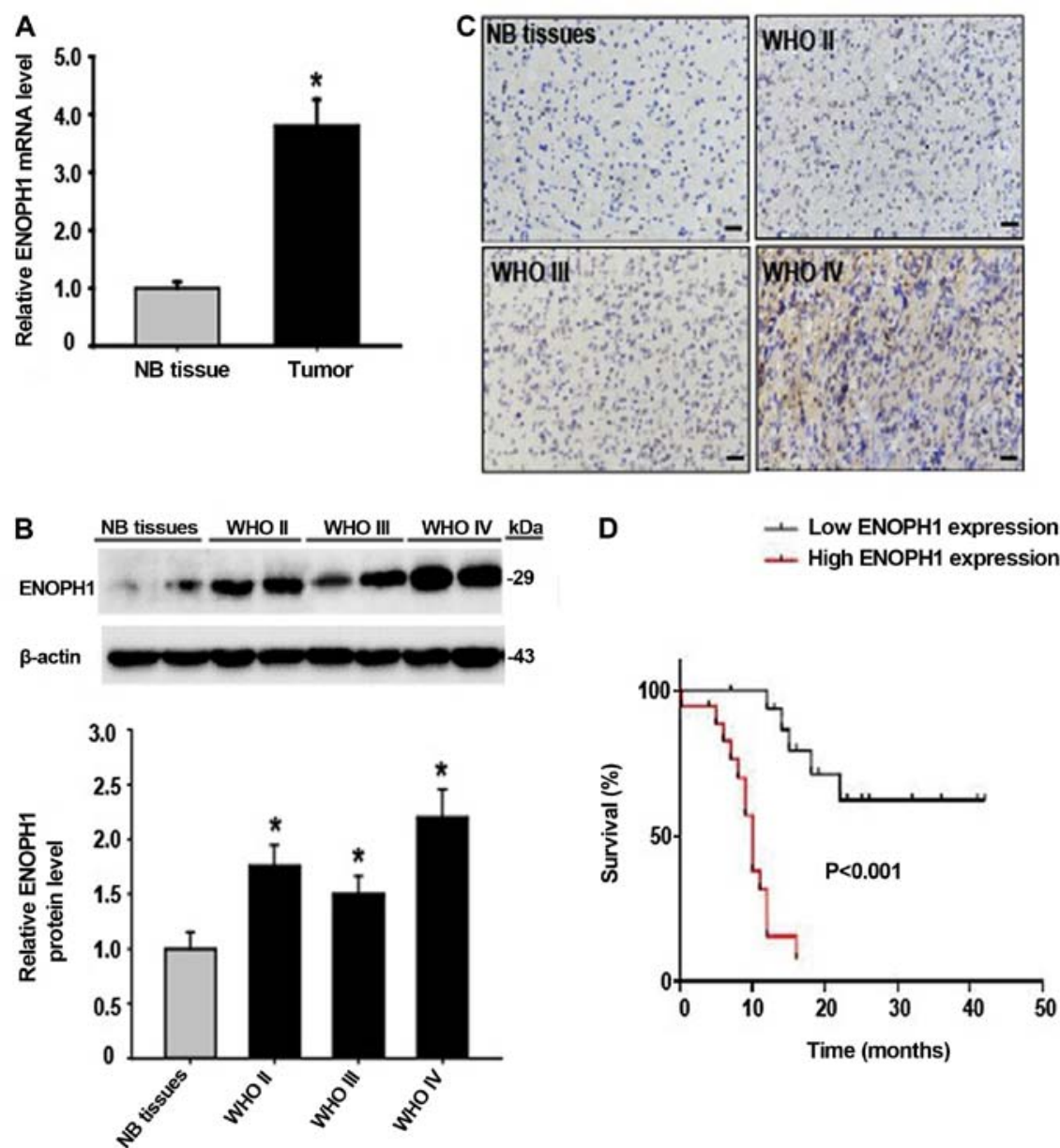

Figure 1. Expression of ENOPH1 in glioma tissues and normal brain tissues. (A) The real time RT-PCR assay revealed an increased expression of ENOPH1 mRNA in glioma tissues in contrast to normal brain tissues. " $\mathrm{P}<0.05$ vs. NB tissues. (B) Western blot analysis revealed ENOPH1 protein expression in glioma tissue samples compared with NB tissues. Upper panel: Representative immunoblots of ENOPH1 and the loading control $\beta$-actin; bottom panel: Quantitative data of protein band intensity following normalization to $\beta$-actin, ${ }^{*} \mathrm{P}<0.05$ vs. NB tissues; the unpaired t-test was used for this assay. (C) Immunohistochemical staining revealed incremental levels of ENOPH1 in glioma samples (especially WHO IV grade glioma tissues) in contrast to NB tissues. ENOPH1 was located in the cytosol and nuclei (Scale bars, $50 \mu \mathrm{m}$ ). "P<0.05 vs. NB tissues. An unpaired t-test was used for this assay. NB, normal brain tissues. (D) Kaplan-Meier survival analysis in primary glioma cases stratified by ENOPH1 expression indicated that high levels of ENOPH1 expression were associated with shorter overall survival. $\mathrm{P}<0.001$ vs. the low level of ENOPH1 expression group. Low, low level of ENOPH1 expression group; high, high level of ENOPH1 expression group. ENOPH1, enolase-phosphatase 1; NB, normal brain.

in the progression of glioma, we first studied the ENOPH1 expression changes in human glioma tissue. By real-time RT-PCR, we observed that ENOPH1 mRNA expression in glioma tissue was significantly increased ( 4-fold) compared to normal brain tissue (Fig. 1A). In accordance with its mRNA change, ENOPH1 protein levels were markedly increased as well in human glioma tissue, especially in the WHO grade IV samples (Fig. 1B). IHC analysis revealed that the expression of ENOPH1 was mainly localized in the nucleus in the WHO grade II and III glioma samples, in contrast to normal brain samples, while in the WHO grade IV glioma samples, ENOPH1 was mainly localized in the cytoplasm of the cells (Fig. 1C). Subsequenlty, we investigated the association between ENOPH1 expression and overall survival using Kaplan-Meier survival curve analysis. We observed that a high level of ENOPH1 expression was associated with a shorter overall survival (Fig. 1D). Thus, these results indicated that ENOPH1 was upregulated in glioma patients, and its expression was significantly associated with clinicopathological grade and survival status. For the remainder of the present study we selected extensively used in vitro human glioma malignant cell lines (i.e., U87 and U251), in order to investigate the role of ENOPH1 in glioma pathophysiology and to demonstrate the underlying mechanisms involved.

ENOPH1 expression is increased in glioma cell lines. Taking into account the findings that ENOPH1 expression was increased in human glioma tissues, we determined the level of ENOPH1 in vitro. We performed qPCR analysis as well as western blotting to determine the expression of ENOPH1 in glioma cell lines (U87 and U251). ENOPH1 mRNA expression was significantly increased in U87 (2.02-fold) and U251 (2.30-fold) glioma cells compared with human astrocyte cells, as demonstrated in Fig. 2A. Similar results were also observed at the protein level (Fig. 2B). To reveal the intracellular localization of ENOPH1 in glioma cell lines, we performed immunocytochemical staining to further verify the immunoblot findings. It was demonstrated by immunostaining that ENOPH1 protein was found in the cytosol and nucleus (Fig. 2C) and the fluorescence intensity of ENOPH1 

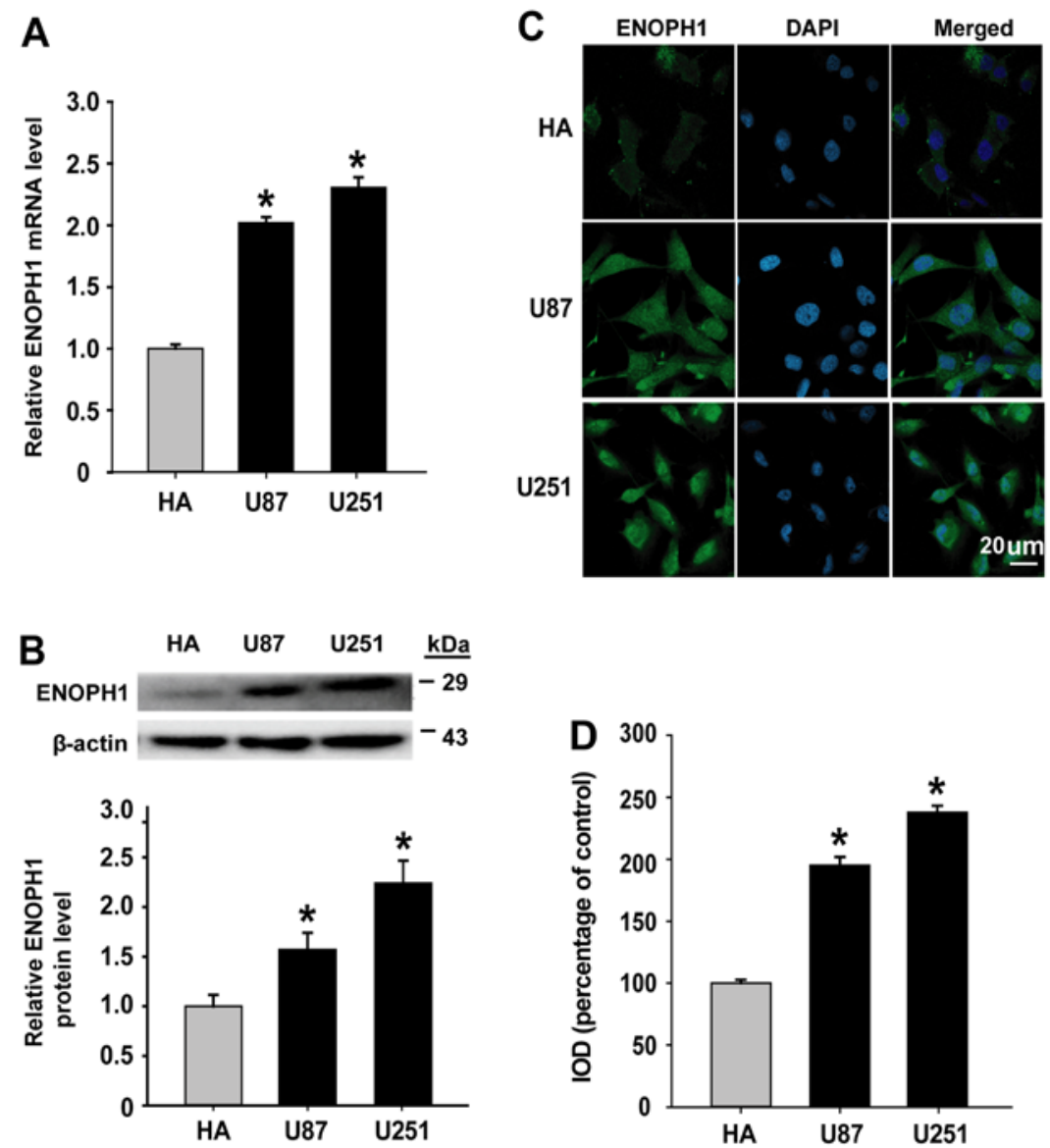

Figure 2. Expression of ENOPH1 in glioma cell lines. (A) RT-qPCR analysis revealed that the increase of ENOPH1 mRNA expression was significant in U87 and $\mathrm{U} 251$ glioma cells compared with HA cells by qPCR assays. Data are presented as the mean $\pm \mathrm{SD}$ for three independent experiments ("P<0.05). (B) Western blot analysis of the increased ENOPH1 protein expression in U87 and U251 glioma cells compared with HA cells. Upper panel: Representative immunoblots of ENOPH1 and the loading control $\beta$-actin; bottom panel: Quantitative data of protein band intensity following normalization to $\beta$-actin. " $\mathrm{P}<0.05$ vs. $\mathrm{HA} ; \mathrm{n}=3$. The unpaired t-test was used for this assay. (C) Two glioma cell lines (U87 and U251) were engaged in immunostaining with ENOPH1 (green), and the nuclei were counterstained with DAPI (blue). Representative immunocytochemical micrographs revealed that ENOPH1 was present in the cytosol and the increase of ENOPH1 fluorescence intensity was significant in U87 and U251 glioma cells compared with HA cells (scale bar, $20 \mu \mathrm{m}$ ). (D) As an integral optical density (IOD) parameter, the intensities of ENOPH1 immunofluorescence were quantitated and expressed. " $\mathrm{P}<0.05$ vs. HA; $\mathrm{n}=3$. ENOPH1, enolase-phosphatase 1; HA, human astrocytes.

was significantly increased in U87 $(\sim 1.95$-fold increase) and U251 ( 2.38-fold increase) glioma cells compared with human astrocyte cells (Fig. 2D). Notably the expression of ENOPH1 in glioma cells was upregulated.

Knockdown of ENOPH1 inhibits glioma cell proliferation and migration. To identify the cellular mechanisms responsible for tumor proliferation and migration, MTT and scratch assays were performed, respectively. First, by RNA disturbance (RNAi) in high-grade glioma cells we inhibited ENOPH1 gene expression, using both the U87 and U251 cells. The evaluation of the silencing effects of siRNA was also confirmed by western blotting (Fig. 3A). Subsequently, using MTT assay we detected the proliferation of U251 cells following transfection with ENOPH1 siRNA. A powerful growth ability was demonstrated by U251 cells, which was attenuated significantly by knockdown of ENOPH1 in a time-dependent manner, particularly at 72 and $96 \mathrm{~h}(\mathrm{P}<0.05)$ post-transfection of ENOPH1 siRNA (Fig. 3B). Subsequently, using a microscope, the degree of wound healing was evaluated by scratch analysis every $24 \mathrm{~h}$. Representative images of U87 and U251 cells acquired at $48 \mathrm{~h}$ are displayed (Fig. 3C and D); the former (U87) was inhibited by $36 \%$ and the latter (U251) by $44 \%$ (Fig. 3E). Our data indicated that downregulation of ENOPH1 inhibited glioma cell proliferation and migration.

Knockdown of ENOPH1 results in a block of the G2/M transition. By PI staining and flow cytometry, the possible effects of ENOPH1 knockdown on cell cycle progression were evaluated. An increase in cells at the G2/M phase was found as a result of depletion of ENOPH1 in U251 cells (Fig. 4A and B). The assessment of the effects of ENOPH1 siRNA transfection on the protein levels of the cell-cycle key regulators p21, p27, cyclin B and cyclin D was performed using western blotting. It was demonstrated in Fig. $4 \mathrm{C}$ that the expression of p21 and p27 was upregulated, while that of cyclin B and cyclin D was downregulated in the ENOPH1 siRNA group, when compared with the astrocyte group. These results demonstrated that knocked down ENOPH1 expression blocks the cell cycle G2/M transition.

Downregulation of ENOPH1 inhibits MT1-MMP expression in glioma cells. Previous studies have revealed that the downstream molecule ADI1 of ENOPH1 can tie up and knock 
A

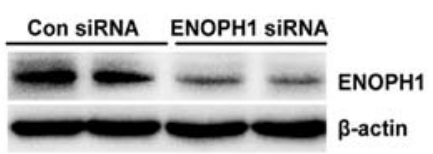

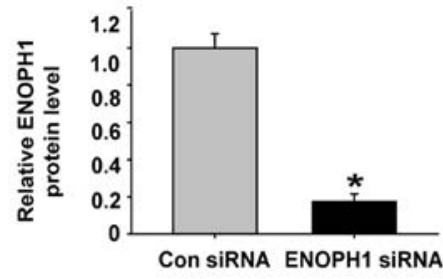

C Con SIRNA ENOPH1 SIRNA
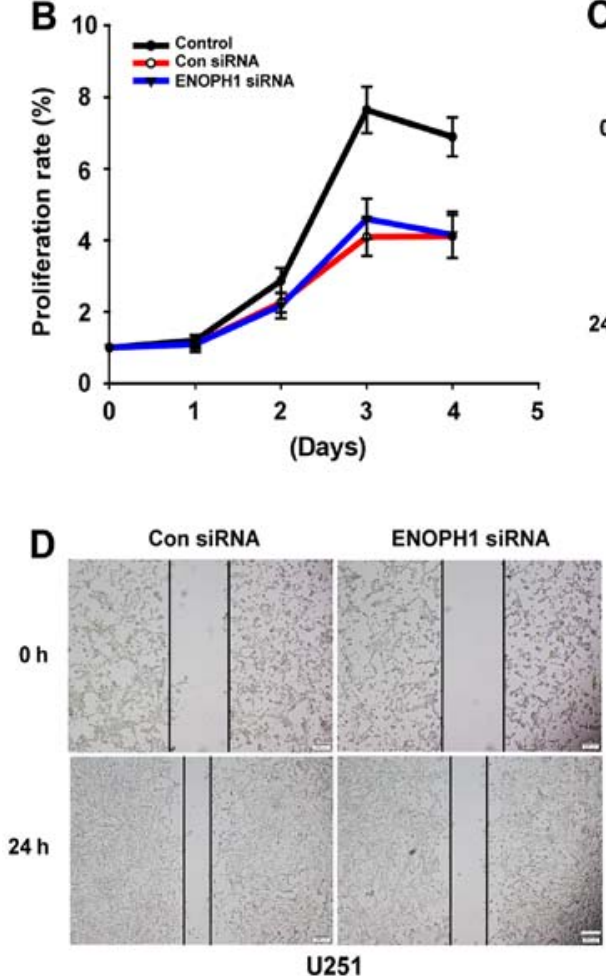

on

$24 \mathrm{~h}$

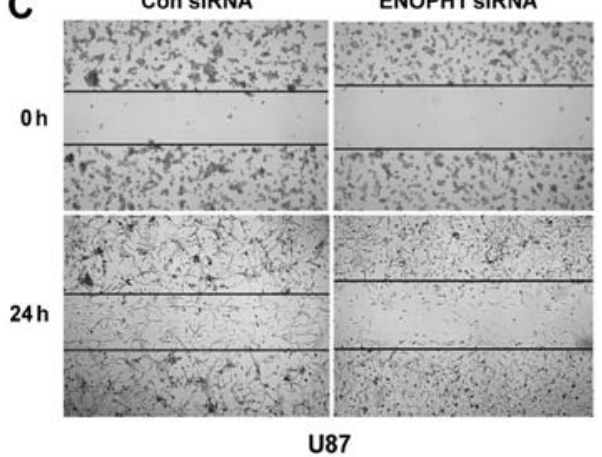

E

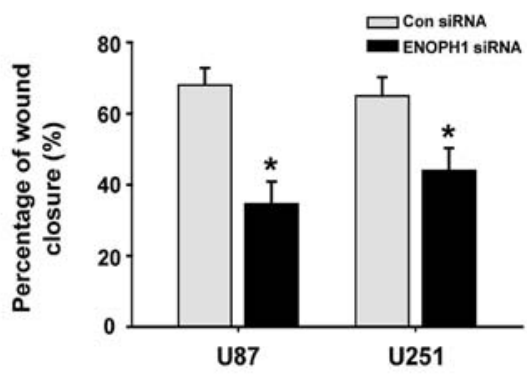

Figure 3. ENOPH1 knockdown attenuates cancer progression in glioma cells. (A) Western blot analysis revealed that a significant ( 80\%) reduction of ENOPH1 protein levels resulted from incubation of U251 cells with ENOPH1 siRNA for $48 \mathrm{~h}$. Left panel: Representative immunoblots of ENOPH1; right panel: Quantitative data of the protein band intensity. ${ }^{~} \mathrm{P}<0.05$ vs. control siRNA; $\mathrm{n}=4$. (B) Effects of ENOPH1 silencing on the proliferation of U87 and U251 cells. Migration of (C) U87 cells and (D) U251 cells transfected with ENOPH1 siRNAs were identified by wound healing assays. Scale bars, $200 \mu \mathrm{m}, \mathrm{n}=3$. (E) Quantitation of U87 and U251 cell migration into the scratch using ImageJ software. "P<0.05 vs. control siRNA; n=3. ENOPH1, enolase-phosphatase 1 .

down the activity of membrane-type matrix metalloproteinase (MT1-MMP) (22,23), and it is known that, MT1-MMP contributes to human malignant glioma aggressiveness $(24,25)$. Thus, we hypothesized that the effect of ENOPH1 on glioma progression may be mediated by the ADI1/MT1-MMP pathway. To investigate this possibility, we examined the effect of ENOPH1 silencing on its downstream protein ADI1 and MT1-MMP expression. We first used western blotting to investigate the ADI1 protein level in human malignant cell lines. We observed that the increase of ADI1 protein levels was significant in U87 and U251 glioma cells compared with human astrocyte cells (Fig. 5A and B). Subsequently, we determined the effect of ENOPH1 knockdown on ADI1 intracellular distribution. The data demonstrated that ENOPH1 downregulation reduced ADI1 protein levels in $\mathrm{CN}$ (cytosolic nuclei), while its protein level in the $\mathrm{CF}$ (cytosolic fraction) was increased in U251 glioma cells (Fig. 5C). In addition, the expression of MT1-MMP protein was significantly decreased in the ENOPH1-siRNA transfection group compared with the control group (Fig. 5D). Collectively, these data indicated that ENOPH1 may indirectly promote MT1-MMP expression through the inhibition of ADI1 translocation from the nucleus to the cytosol in human malignant glioma cells.

\section{Discussion}

ENOPH1, as the methionine salvage pathway enzyme, has been revealed to play a role in stress reactivity (10) and ischemic blood-brain barrier (BBB) dysfunction (21). However, its possible effects on glioma progression and potential mechanisms have not been fully elucidated. The present study provided the first evidence that ENOPH1 contributed to glioma proliferation and migration in vitro. The major findings included the following: i) ENOPH1 was markedly upregulated in human glioma tissues and malignant glioma cells (U87 and U251 cell lines), respectively; ii) knockdown of ENOPH1 with siRNA significantly attenuated glioma cell proliferation; iii) knockdown of ENOPH1 attenuated glioma cell migration; and iv) knockdown of ENOPH1 induced ADI1 to translocate from the nucleus to the cytosol and may promote the separation of ADI1 from MT1-MMP in the cytoplasm, and in glioma cells, downregulating MT1-MMP expression. 
A
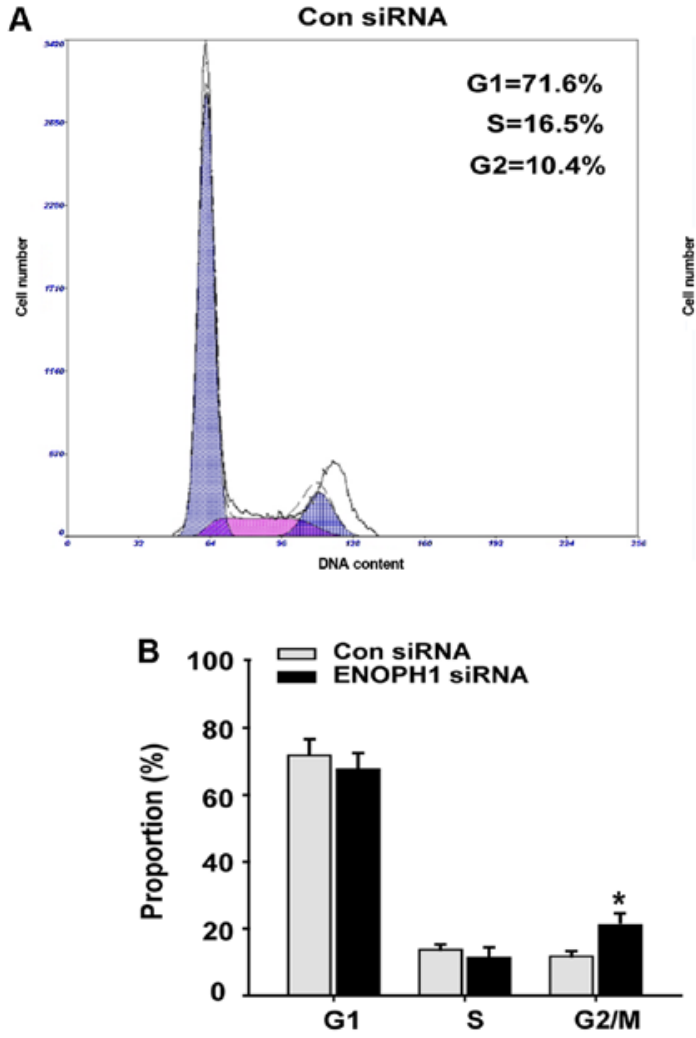
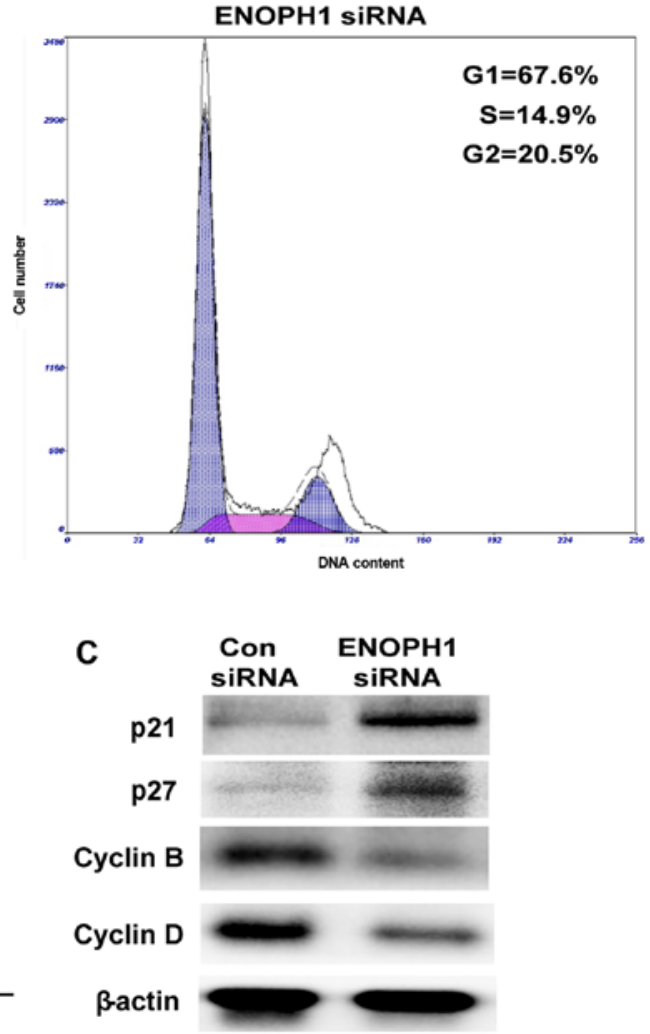

Figure 4. Suppressing ENOPH1 expression inhibited the phase transition of G2/M in glioma cells. (A and B) The U251 cells were transfected with the indicated siRNA and the cells were collected $48 \mathrm{~h}$ later. The analysis of the cell cycle profile was performed by flow cytometry. Left panel: Representative images of control siRNA; right panel: Representative images of ENOPH1 siRNA. * $\mathrm{P}<0.05$ vs. control siRNA; $\mathrm{n}=3$. (C) The protein levels of the cell cycle key regulators (p21, p27, cyclin D and cyclin B) in U251 cells were detected by western blot analysis. $\mathrm{n}=3$. ENOPH1, enolase-phosphatase 1 .

In glioma, polyamine synthesis is increased and can spread to the surrounding tissues. Key enzyme-ODC activity increases in a positive correlation with the degree of tumor malignancy and, can be used as a reliable indicator of glioma malignancy $(26,27)$. Other evidence revealed that ENOPH1 via S-adenosyl methionine (SAM) plays an indirect role in the synthesis of polyamine (14-17). At present, the biological functions of ENOPH1 are still mainly not known. It has been revealed in a few recent studies that there is wide expression of ENOPH1 in the brain and it is related to neurodevelopmental disorders, anxiety behavior and BBB function integrity damage $(10,21,28)$. The present study was the first investigation of the role of ENOPH1 in the pathophysiology of gliomas. Our data revealed that ENOPH1 upregulation existed not only in the glioma cell lines but also in human glioma tissue, especially in glioblastomas. Notably, ENOPH1 was mainly located in the nucleus in normal brain tissue, WHO II and WHO III grade tissue samples, but in WHO IV grade tissue, ENOPH1 was translocated to the cytoplasm, which was consistent with the findings in U87 and U251 malignant glioma cells. According to these results, we hypothesized that the occurrence of gliomas and the transition of gliomas from low- to high-grade may be facilitated by the translocation of ENOPH1 from the nucleus to the cytoplasm. In previous studies, there was no similar data to support this translocation, and we believe a possible reason for this is that polyamine accumulation promoted ENOPH1 activation and that ENOPH1 is a tumor microenvironment stress factor. Further experiments are warranted to analyze this phenomenon and mechanism.
This is the first study of the role of ENOPH1 in cell proliferation and migration in order to determine the molecular mechanism of the effect of ENOPH1 on the progression of glioma. We revealed a reduction of cellular proliferation rate and the degree of wound healing produced by knockdown of ENOPH1 with siRNA, which obviously implicated ENOPH1 in glioma cell growth and migration. In addition, in the assay of cell cycle progression, we observed downregulation of cyclin B and cyclin D following knockout of ENOPH1 which promoted a G2/M phase arrest, whereas there was upregulation of p21 and p27, further supporting a promoting role of ENOPH1 in glioma development.

ADI1 (also known as MTCBP1), a methionine salvage pathway enzyme, is a downstream molecule of ENOPH1 and has been indicated to be connected with cell apoptosis, oxidative stress, microbial infection and reproductive development (29-32). In addition, as an oxidoreductase, ADI1 can collect molecular oxygen donor to generate ROS (30). A recent study illustrated a new role for ADI1 in regulating MT1-MMP-mediated autophagy, which is important in glioblastoma cells (33). The high expression of MT1-MMP in malignant glioma tissue and its close relationship to the progression and invasion of glioma are well-known (34-36). These research data led us to hypothesize that the effect of ENOPH1 on glioma progression may be mediated by the ADI1/MT1-MMP pathway. Our in vitro study revealed that knockdown of ENOPH1 promoted ADI1 translocation from the nucleus to the cytoplasm and the expression of MT1-MMP was decreased. According to these evidence, we hypothesized 
A
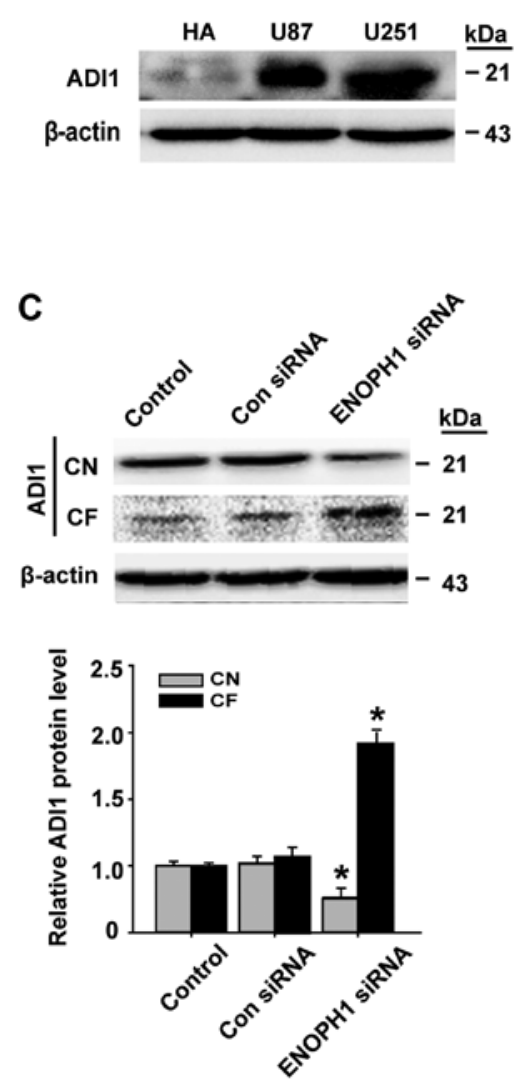
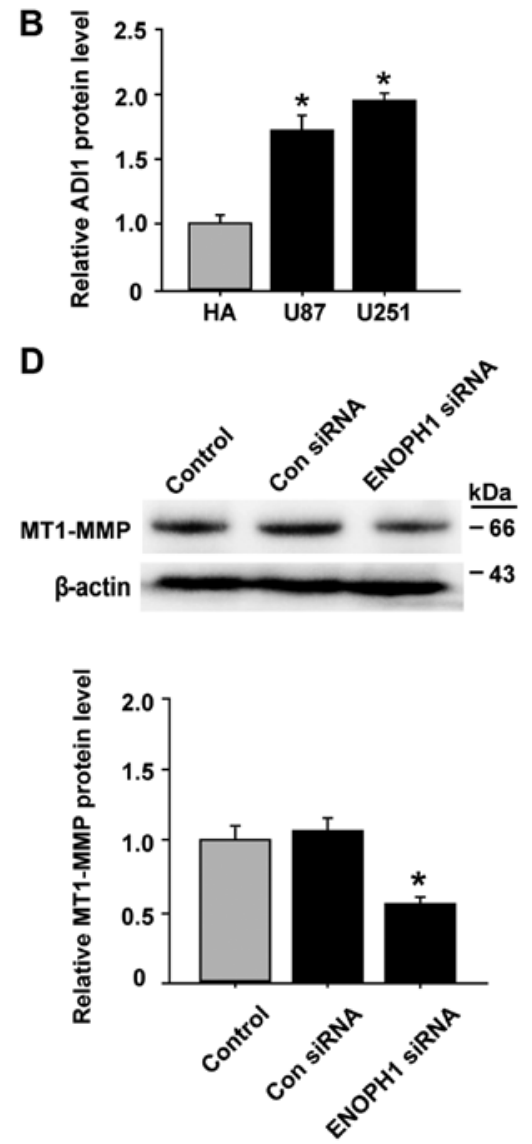

Figure 5. Effect of ENOPH1 knockdown on ADI and MT1-MMP expression in U251 glioma cells. (A and B) Western blot analysis of ADI1 protein levels in U87 and U251 glioma cells compared with HA cells. Representative immunoblots of ADI1 and the loading control $\beta$-actin. (B) Quantitative data of protein band intensity following normalization to $\beta$-actin. ${ }^{*} \mathrm{P}<0.05$ vs. HA; $n=3$. (C) Upper panel: Representative immunoblots of ADI1 and the loading control $\beta$-actin; bottom panel: The data illustrated quantitatively revealing markedly reduced ADI1 levels in CN compared with its increased level in the CF in U251 glioma cells transfected by ENOPH1 siRNA. "P<0.05 vs. the control; $n=3$. (D) Upper panel: Representative immunoblots of MT1-MMP and the loading control $\beta$-actin; bottom panel: Quantitative data illustrating that MT1-MMP protein expression was markedly decreased in the ENOPH1-siRNA group. "P<0.05 vs. the control; $\mathrm{n}=3$. ENOPH1, enolase-phosphatase 1; ADI1, aci-reductone dioxygenase 1; HA, human astrocytes; $\mathrm{CF}$, cytosolic fraction; CN, cytosolic nuclei.

that ENOPH1 may promote ADI1 migration into the nucleus and separate MT1-MMP from ADI1 in the cytoplasm, attenuating the inhibitory effect of ADI1 on MT1-MMP, and indirectly enhancing MMP-2 activity, further promoting glioma cell proliferation and migration. Future studies are warranted to perform animal experiments in vivo to detect the activity of MT1-MMP and the interaction of ENOPH1 with ADI1, as well as the interaction between ADI1 and MT1-MMP in glioma cell lines.

In conclusion, our results collectively provided preliminary evidence of the role of ENOPH1 in glioma progression, in which increased cellular growth and migration can be caused by ENOPH1 upregulation in glioma cells. In addition, Knockdown of ENOPH1 facilitated its downstream molecule ADI1, to translocate from the nucleus to the cytoplasm, and indirectly decreased the expression of MT1-MMP in glioma cells. Investigation of the mechanisms underlying this change need to be identified in future studies. In addition, the expression of ENOPH1 can be used as an unfavorable progression indicator for glioma patients.

\section{Acknowledgements}

Not applicable.

\section{Funding}

The present study was funded by grants from the National Natural Science Foundation of China (no. 81760227), the Natural Science Foundation of Inner Mongolia Autonomous Region of China (no. 2016MS0802), the Natural Science Foundation of Guangdong Province (no. 2017A030313568) and the Science Research Fund Project of Baotou Medical College (no. BYJJ-DF201601).

\section{Availability of data and materials}

All data generated or analyzed during this study are included in this published article.

\section{Authors' contributions}

LS, YZ and GX conceived and planned the experiments. LS, JH and KY conducted the experiments. SL and CL collected the clinical samples. LS, YZ and KY analyzed the data. LS and $\mathrm{KY}$ contributed to the reagent material and analysis tools. YZ and GX wrote the paper. All authors read and approved the manuscript and agree to be accountable for all aspects of the research in ensuring that the accuracy or integrity of any part of the work are appropriately investigated and resolved. 


\section{Ethics approval and consent to participate}

All experiments using human samples were approved by the Ethics Committee of Southern Medical University. All patients willingly consented to participate in the study by signing an informed consent form.

\section{Patient consent for publication}

Not applicable.

\section{Competing interests}

The authors declare that they have no competing interests.

\section{References}

1. Eckel-Passow JE, Lachance DH, Molinaro AM, Walsh KM, Decker PA, Sicotte H, Pekmezci M, Rice T, Kosel ML, Smirnov IV, et al: Glioma Groups Based on 1p/19q, IDH, and TERT Promoter Mutations in Tumors. N Engl J Med 372: 2499-2508, 2015.

2. Omuro A and DeAngelis LM: Glioblastoma and other malignant gliomas: A clinical review. JAMA 310: 1842-1850, 2013.

3. Pesenti C, Paganini L, Fontana L, Veniani E, Runza L, Ferrero S, Bosari S, Menghi M, Marfia G,Caroli M, et al: Mass spectrometrybased assay for the molecular diagnosis of glioma: Concomitant detection of chromosome $1 \mathrm{p} / 19 \mathrm{q}$ codeletion, and IDH1, IDH2, and TERT mutation status. Oncotarget 8: 57134-57148, 2017.

4. Karsy M, Guan J, Cohen AL, Jensen RL and Colman H: New molecular considerations for glioma: IDH, ATRX, BRAF, TERT, H3 K27M. Curr Neurol Neurosci Rep 17: 19, 2017.

5. Holland EC: Progenitor cells and glioma formation. Curr Opin Neurol 14: 683-688, 2001.

6. Tang W, Wang X, Chen Y, Zhang J, Chen Y and Lin Z: CXCL12 and CXCR4 as predictive biomarkers of glioma recurrence pattern after total resection. Pathol Biol (Paris) 63: 190-198, 2015.

7. Sun L, Song L, Wan Q, Wu G, Li X, Wang Y, Wang J, Liu Z, Zhong X, He X, et al: cMyc-mediated activation of serine biosynthesis pathway is critical for cancer progression under nutrient deprivation conditions. Cell Res 25: 429-444, 2015.

8. Adams S, Teo C, McDonald KL, Zinger A, Bustamante S, Lim CK, Sundaram G, Braidy N, Brew BJ and Guillemin GJ: Involvement of the kynurenine pathway in human glioma pathophysiology. PLoS One 9: e112945, 2014.

9. Sauter M, Moffatt B, Saechao MC, Hell R and Wirtz M: Methionine salvage and S-adenosylmethionine: Essential links between sulfur, ethylene and polyamine biosynthesis. Biochem J 451: 145-154, 2013

10. Barth A, Bilkei-Gorzo A, Drews E, Otte DM, Diaz-Lacava A, Varadarajulu J, Turck CW, Wienker TF and Zimmer A: Analysis of quantitative trait loci in mice suggests a role of Enoph1 in stress reactivity. J Neurochem 128: 807-817, 2014.

11. Morita K, Lee MS, Her S and Nishibori N: Polyamines cause elevation of steroid $5 \alpha$-reductase mRNA levels by suppressing mRNA degradation in C6 glioma cells. Cell Biol Int 38: 1132-1137, 2014.

12. Elworthy P and Hitchcock E: Red blood cell polyamines as a diagnostic indicator of glioma presence and recurrence. J Neurooncol 7 : 31-38, 1989

13. Redgate ES, Boggs S, Grudziak A and Deutsch M: Polyamines in brain tumor therapy. J Neurooncol 25: 167-179, 1995.

14. Takano K, Ogura M, Nakamura Y and Yoneda Y: Neuronal and glial responses to polyamines in the ischemic brain. Curr Neurovasc Res 2: 213-223, 2005.

15. Li J, Doyle KM and Tatlisumak T: Polyamines in the brain: Distribution, biological interactions, and their potential therapeutic role in brain ischaemia. Curr Med Chem 14: 1807-1813, 2007.

16. Duan B, Wang YZ, Yang T, Chu XP, Yu Y, Huang Y, Cao H, Hansen J, Simon RP, Zhu MX, et al: Extracellular spermine exacerbates ischemic neuronal injury through sensitization of ASICla channels to extracellular acidosis. J Neurosci 31: 2101-2112, 2011.

17. Kim GH, Komotar RJ, McCullough-Hicks ME, Otten ML, Starke RM, Kellner CP, Garrett MC, Merkow MB, Rynkowski M, Dash KA, et al: The role of polyamine metabolism in neuronal injury following cerebral ischemia. Can J Neurol Sci 36: 14-19, 2009.
18. Louis DN, Ohgaki H, Wiestler OD, Cavenee WK, Burger PC, Jouvet A, Scheithauer BW and Kleihues P: The 2007 WHO classification of tumours of the central nervous system. Acta Neuropathol 114: 97-109, 2007.

19. Zhang Y, Zeng Y, Wang M, Tian C, Ma X, Chen H, Fang Q, Jia L, Du J and Li H: Cardiac-specific overexpression of E3 ligase Nrdp1 increases ischemia and reperfusion-induced cardiac injury. Basic Res Cardiol 106: 371-383, 2011.

20. Livak KJ and Schmittgen TD: Analysis of relative gene expression data using real-time quantitative PCR and the 2(-Delta Delta C(T)) method. Methods 25: 402-408, 2001.

21. Zhang Y, Wang T, Yang K, Xu J, Ren L, Li W and Liu W: Cerebral Microvascular Endothelial Cell Apoptosis after ischemia: Role of enolase-phosphatase 1 activation and aci-reductone dioxygenase 1 translocation. Front Mol Neurosci 9: 79, 2016.

22. Uekita T, Gotoh I, Kinoshita T, Itoh Y, Sato H, Shiomi T, Okada Y and Seiki M: Membrane-type 1 matrix metalloproteinase cytoplasmic tail-binding protein-1 is a new member of the Cupin superfamily. A possible multifunctional protein acting as an invasion suppressor down-regulated in tumors. J Biol Chem 279: 12734-12743, 2004.

23. Chang ML, Huang $\mathrm{YH}$, Cheng JC and Yeh CT: Interaction between hepatic membrane type 1 matrix metalloproteinase and acireductone dioxygenase 1 regulates hepatitis $\mathrm{C}$ virus infection. J Viral Hepat 23: 256-266, 2016.

24. Chen S, Han M, Chen W, He Y, Huang B, Zhao P, Huang Q, Gao L, Qu X and Li X: KIF1B promotes glioma migration and invasion via cell surface localization of MT1-MMP. Oncol Rep 35: 971-977, 2016.

25. Mou L, Kang Y, Zhou Y, Zeng Q, Song H and Wang R: Neurokinin-1 receptor directly mediates glioma cell migration by up-regulation of matrix metalloproteinase-2 (MMP-2) and membrane type 1-matrix metalloproteinase (MT1-MMP). J Biol Chem 288: 306-318, 2013

26. Ernestus RI, Röhn G, Schröder R, Els T, Klekner A, Paschen W and Klug N: Polyamine metabolism in brain tumours: Diagnostic relevance of quantitative biochemistry. J Neurol Neurosurg Psychiatry 71: 88-92, 2001.

27. Hoelzinger DB, Nakada M, Demuth T, Rosensteel T, Reavie LB and Berens ME: Autotaxin: A secreted autocrine/paracrine factor that promotes glioma invasion. J Neurooncol 86: 297-309, 2008.

28. Komlósi K, Duga B, Hadzsiev K, Czakó M, Kosztolányi G, Fogarasi A and Melegh B: Phenotypic variability in a Hungarian patient with the $4 \mathrm{q} 21$ microdeletion syndrome. Mol Cytogenet 8: $16,2015$.

29. Hirano W, Gotoh I, Uekita T and Seiki M: Membrane-type 1 matrix metalloproteinase cytoplasmic tail binding protein-1 (MTCBP-1) acts as an eukaryotic aci-reductone dioxygenase (ARD) in the methionine salvage pathway. Genes Cells 10: 565-574, 2005.

30. Oram SW, Ai J, Pagani GM, Hitchens MR, Stern JA, Eggener S, Pins M, Xiao W, Cai X, Haleem R, et al: Expression and function of the human androgen-responsive gene ADI1 in prostate cancer. Neoplasia 9: 643-651, 2007

31. Cheng JC, Yeh YJ, Pai LM, Chang ML and Yeh CT: 293 cells over-expressing human ADI1 and CD81 are permissive for serumderived hepatitis C virus infection. J Med Virol 81: 1560-1568, 2009.

32. Chou HY, Lin YH, Shiu GL, Tang HY, Cheng ML, Shiao MS and Pai LM: ADI1, a methionine salvage pathway enzyme, is required for Drosophila fecundity. J Biomed Sci 21: 64, 2014

33. Pratt J, Iddir M, Bourgault S and Annabi B: Evidence of MTCBP-1 interaction with the cytoplasmic domain of MT1-MMP: Implications in the autophagy cell index of high-grade glioblastoma. Mol Carcinog 55: 148-160, 2016.

34. Markovic DS, Vinnakota K, Chirasani S, Synowitz M, Raguet H, Stock K, Sliwa M, Lehmann S, Kälin R, van Rooijen N, et al: Gliomas induce and exploit microglial MT1-MMP expression for tumor expansion. Proc Natl Acad Sci USA 106: 12530-12535, 2009.

35. Markovic DS, Vinnakota K, van Rooijen N, Kiwit J, Synowitz M, Glass R and Kettenmann H: Minocycline reduces glioma expansion and invasion by attenuating microglial MT1-MMP expression. Brain Behav Immun 25: 624-628, 2011.

36. Huang M, Liu T, Ma P, Mitteer RA Jr, Zhang Z, Kim HJ, Yeo E, Zhang D, Cai P, Li C, et al: c-Met-mediated endothelial plasticity drives aberrant vascularization and chemoresistance in glioblastoma. J Clin Invest 126: 1801-1814, 2016. 